\title{
Pemberian Mulsa dan Penguat Teras Pada Tiga Jenis Tanaman Terhadap Limpasan Permukaan, Erosi, Pertumbuhan dan Hasil Tanaman Pada Tanah Andisol
}

\author{
Jaka Suyana2), Sumarno2), Supriyono²), Nanik Puji Lestariningsih ${ }^{1)}$
}

\begin{abstract}
Erosion is the main factor causing land degradation in area of planting vegetables dominated by Andisol soil. Andisol soil contains more fraction of dust so it is easily transported by runoff. This study aim to determine the influence of mulching corn stem with a terrace strengthen (Vetiveria zizanioides, Coix lacryma-jobi L., Panicum muticum, Annona squamosa) to surface runoff, erosion, growth and result of plant (red lentils, cabbage and white lentils) in Andisol soil. This study uses a randomized complete block design with four (4) treatment and repeated three (3) times as a group so that there are twelve (12) experimental unit. The grouping based on kinds of plant that are cabbage, red lentils and white lentils. The results showed that MS4 treatment (mulch corn stem twelve (12) ton/ha with panicum muticum+ Annona squamosa as terrace strengthen) produces smallest of surface run off, erosion and dry weight of weeds, increased growth and canopy and increased crop yields $40.27 \%$ of red lentils, $57.10 \%$ of cabbage and $14.54 \%$ of white lentils.
\end{abstract}

Keywords: Corn stem, canopy, dose, land degradation

\section{PENDAHULUAN}

Erosi merupakan faktor utama penyebab degradasi tanah di kawasan pertanaman sayuran pada tanah Andisol. Tanah Andisol mengandung lebih banyak fraksi debu sehingga sangat mudah terangkut oleh aliran permukaan. Tanah andisol juga memiliki struktur yang remah dan terletak pada lereng yang curam sehingga tanah ini mudah untuk tererosi (Erfandi dan Haryati 2011).

Batang jagung merupakan salah satu sisa tanaman yang belum banyak dimanfaatkan petani sebagai mulsa. Mayoritas petani hanya memanfaatkan biji jagung sedangkang batangnya hanya dijadikan sebagai kayu bakar. Jacks et al. (2007) menyatakan bahwa batang jagung mengandung selulosa dari zat lignin yang tinggi sehingga mudah didekomposisi oleh mikroorganisme.

Pemberian mulsa batang jagung dapat mengurangi erosi, mengurangi kecepatan aliran permukaan, mencegah kehilangan air melalui evaporasi, mengurangi fluktuasi temperatur dan menjaga kelembaban tanah. Mulsa batang jagung dapat dikombinasikan dengan tanaman penguat teras untuk meningkatkan efektifitasnya menahan limpasan permukaan dan erosi. Tanaman penguat teras tersebut mengurangi panjang lereng, memperlambat laju aliran

\footnotetext{
1)Lecturer Staff of Study Program of Agrotechnology, Faculty of Agriculture, Sebelas Maret University (UNS) on Surakarta.

2) Undergraduate Student of Study Program of Agrotechnology, Faculty of Agriculture, Sebelas Maret University (UNS) on Surakarta.

Contact Author: nanikpuji669@yahoo.co.id
}

permukaan dan menahan tanah yang tererosi dari bidang olah (Blancocanqui et al. 2006).

Tanaman kara merah dan kara putih merupakan tanaman lokal adaptif yang mempunyai potensi untuk dikembangkan dalam menekan erosi dan limpasan permukaan. Penelitian Karuniawan (2011) menunjukkan bahwa lahan yang ditumpangsari dengan kara merah mampu menurunkan erosi sebesar $65,09 \%$. Tanaman kara merah dan kara putih juga memiliki adaptasi iklim yang luas dan dapat tumbuh pada lahan subotimal lahan kering.

Tujuan penelitian ini adalah untuk mengetahui pengaruh mulsa batang jagung dengan tanaman penguat teras terhadap limpasan permukaan, erosi, pertumbuhan dan hasil tanaman kara merah, kubis dan kara putih.

\section{BAHAN DAN METODE}

Penelitian dilaksanakan di Desa Setren, Kecamatan Slogohimo, Kabupaten Wonogiri pada bulan April sampai Juli 2015. Analisis erosi dan limpasan permukaan dilaksanakan di Laboratorium Kimia dan Kesuburan Tanah Fakultas Pertanian Universitas Sebelas Maret Surakarta. Penelitian ini merupakan penelitian petak percobaan erosi yang menggunakan Rancangan Acak Kelompok dengan 4 perlakuan dan diulang 3 kali sebagai blok sehingga terdapat 12 satuan percobaan.

Pengelompokan berdasarkan jenis tanaman yaitu kubis, tanaman kara merah dan tanaman kara putih. Adapun perlakuannya meliputi:

MS1: Pemberian mulsa batang jagung 0 ton/ha tanpa tanaman penguat teras 
MS2: Pemberian mulsa batang jagung 4 ton/ha dengan akar wangi+srikaya sebagai tanaman penguat teras

MS3: Pemberian mulsa batang jagung 8 ton/ha dengan tanaman jali+srikaya sebagai tanaman penguat teras

MS4: Pemberian mulsa batang jagung 12 ton/ha dengan rumput kolonjono+ srikaya sebagai tanaman penguat teras

\section{HASIL DAN PEMBAHASAN}

\section{Limpasan permukaan}

Hujan akan menimbulkan limpasan permukaan jika intensitasnya cukup tinggi dan jatuhnya dalam waku yang relatif lama. Air hujan yang jatuh menimpa tanah di lahan yang terbuka akan menyebabkan tanah terdispersi. Nearing et al. (2007) menyatakan bahwa jika intensitas hujan melebihi kapasitas infiltrasi tanah, maka sebagian air hujan yang jatuh akan mengalir menjadi aliran permukaan. Banyaknya air yang mengalir di permukaan tanah bergantung pada hubungan antara intensitas hujan dengan kapasitas infiltrasi tanah.

Hasil penelitian menunjukkan bahwa perlakuan MS4 berdeda nyata dengan perlakuan MS1. Perlakuan MS4 menghasilkan limpasan permukaan paling kecil yaitu $677,54 \mathrm{~m}^{3} / \mathrm{ha}$ dengan penurunan limpaan $4,46 \%$ (Tabel 1). Hal ini disebabkan mulsa batang jagung mampu menjaga agregat tanah tetap baik karena mengurangi energi pukulan air hujan serta mengurangi aliran permukaan yang dapat mengikis tanah. Djajadi (2008) menyatakan bahwa pemberian mulsa dapat mengurangi penguapan serta terhindar dari pukulan langsung butir-butir air hujan. Mulsa juga memiliki fungsi lain yaitu memperkuat agregat dan porositas tanah, mengurangi kecepatan dan daya kikis aliran permukaan (Ludwig et al 2009).

Jenis tanaman juga mempengaruhi limpasan permukaan, dimana tanaman kara merah menghasilkan limpasan permukaan paling kecil yaitu $680,96 \mathrm{~m}^{3} / \mathrm{ha}$ (Tabel 1). Hal ini berhubungan dengan tutupan kanopi tanaman, dimana semakin rapat dan tertutup kanopi tanaman maka
Data erosi dan limpasan permukaan dianalisis dengan sidik ragam (ANOVA) apabila berbeda nyata dilanjutkan dengan uji DMRT (Duncan's Multiple Range Test) taraf 5\%. Data pertumbuhan dan hasil tanaman kara merah, kubis dan kara putih dianalisis secara Deskriptif.

kapasitas intersepsinya tinggi sedangkan pada tutupan kanopi yang jarang maka kapasitas intersepsinya rendah (Rico and Smith 2011). Tanaman kara merah dan kubis memiliki tutupan tajuk yang rapat sehingga kapasitas intersepsinya tinggi. Kanopi atau tajuk tanaman dapat memecahkan energi butir hujan yang jatuh sehingga energinya berkurang saat membentur permukaan tanah

David et al. (2006) menyatakan bahwa limpasan permukaan yang tidak terlalu besar, hancuran partikel-partikel tanah dapat menutupi pori-pori tanah dibawahnya, hal ini menyebabkan tata udara tanah akan rusak dan tanah menjadi padat. Tanah pada daerah yang berlereng menyebabkan lapisan olah tanah akan dihanyutkan. Curah hujan tinggi dengan keadaan tanah yang kurang kuat ikatannya, selain meningkatkan limpasan permukaan juga meningkatkan terangkutnya partikel-pertikel tanah.

Air hujan yang diintersepsi tanaman sampai permukaan tanah dalam bentuk lolosan tajuk maupun aliran batang mengalir secara perlahan sehingga erosivitasnya berkurang. Air hujan mengalir secara perlahan dari tegakan batang tanaman ke permukaan tanah akan lebih banyak terinfiltrasi. Pertumbuhan kanopi kara putih yang lambat mengakibatkan air hujan jatuh lebih banyak mengalir sebagai limpasan permukaan sehingga pada tanaman koro putih menghasilkan limpasan permukaan paling besar (Walling 2008). Adapun hasil perhitungan limpasan permukaan disajikan pada Tabel 1.

Tabel 1. Pengaruh mulsa dengan penguat teras terhadap limpasan permukaan pada bulan April-Juli 2015.

\begin{tabular}{|c|c|c|c|c|c|c|c|}
\hline \multirow{3}{*}{ Mulsa(M)-Penguat teras(S) } & \multirow{3}{*}{$\begin{array}{c}\mathrm{CH} \\
(\mathrm{mm})\end{array}$} & \multicolumn{3}{|c|}{ Blok (jenis tanaman) } & \multirow{3}{*}{$\begin{array}{l}\text { Rata-rata } \\
\left(\mathrm{m}^{3} / \mathrm{ha}\right)\end{array}$} & \multirow{3}{*}{$\begin{array}{l}\text { \% LP } \\
\text { terhad } \\
\text { ap CH }\end{array}$} & \multirow{3}{*}{$\begin{array}{c}\text { Penurunan } \\
\text { limpasan } \\
\text { permukaan } \\
(\%)\end{array}$} \\
\hline & & $\begin{array}{r}\text { Kara } \\
\text { merah }\end{array}$ & Kubis & $\begin{array}{l}\text { Kara } \\
\text { putih }\end{array}$ & & & \\
\hline & & & $\mathrm{m}^{3} / \mathrm{ha}$ & & & & \\
\hline M (0 ton/ha)-S1 (Tanpa) & 262 & 700,42 & 713,06 & 722,58 & $711,02 \mathrm{a}$ & 2,71 & \\
\hline M (4 ton/ha)-S2 (Akar wangi) & 262 & 681,04 & 698,43 & 704,40 & 694,62 a b & 2,46 & 2,42 \\
\hline M (8 ton/ha)-S3 (Tanaman jali) & 262 & 678,43 & 696,65 & 702,65 & $692,58 \mathrm{a} b$ & 2,32 & 4,04 \\
\hline $\begin{array}{c}\text { M (12 ton/ha)-S4 (Rumput kolonjono) } \\
\text { Rata-rata }\end{array}$ & 262 & $\begin{array}{l}663,97 \\
680,96 \text { a }\end{array}$ & $\begin{array}{c}676,76 \\
696,23 \mathrm{ab}\end{array}$ & $\begin{array}{l}691,87 \\
705,38 b\end{array}$ & $677,54 \mathrm{~b}$ & 1,70 & 4,46 \\
\hline
\end{tabular}

Keterangan: Angka yang diikuti huruf yang sama pada kolom atau baris yang sama menunjukkan tidak beda nyata pada uji DMRT (Duncan's Multiple Range Test) taraf $5 \%$. 


\section{Erosi}

Nearing et al. (2005) menyatakan bahwa erosi akan timbul apabila ada kekuatan dispersi dan tenaga pengangkut oleh air hujan yang mengalir di permukaan tanah. Erosi terjadi karena hancurnya butir-butir tanah yang selanjutnya dihanyutkan melalui limpasan permukaan. Erosi akan besar jika limpasan permukaan besar.

Hasil penelitian menunjukkan tanaman koro merah menghasilkan erosi paling kecil yaitu 9,06 ton/ha dengan penurunan erosi $15,52 \%$ (Tabel 2). Hal ini berhubungan dengan akar tanaman, dimana pengaruh akar beberapa jenis tanaman terhadap erosi sangat berbeda satu sama lain. Akar serabut mengikat butir-butir primer tanah, sedangkan sekresi dan sisa tumbuhan yang terombak memberikan senyawa-senyawa kimia yang berfungsi sebagai pemantap agregat. Ludwig et al. (2007) menyatakan bahwa akarakar halus berperan dalam memperkuat kekuatan geser tanah. Tanaman kara merah memiliki perakaran serabut sehingga mampu memperkuat ketahanan tanah terhadap erosi. Tanaman memiliki kemampuan yang berbeda dalam menekan aliran permukaan dan erosi. Efektifitas tanaman dalam mengurangi laju erosi dipengaruhi oleh (1) kanopi atau tajuk tanaman, (2) bahan organik yang dihasilkan, (3) sistem perakaran serta kemampuan tanaman untuk menutup tanah (Rachman et al. 2008).

Tabel 2. Pengaruh perlakuan dan jenis tanaman terhadap erosi pada bulan April-Juli 2015

\begin{tabular}{|c|c|c|c|c|c|c|}
\hline \multirow{3}{*}{ Mulsa(M)-Penguat teras(S) } & \multicolumn{4}{|c|}{ Blok (jenis tanaman) } & \multirow{3}{*}{$\begin{array}{c}\text { Rata-rata } \\
\text { (ton/ha) }\end{array}$} & \multirow{3}{*}{$\begin{array}{c}\text { Penurunan } \\
\text { erosi (\%) }\end{array}$} \\
\hline & $\begin{array}{l}\text { Curah hujan } \\
(\mathrm{mm})\end{array}$ & $\begin{array}{c}\text { Kara } \\
\text { merah }\end{array}$ & Kubis & $\begin{array}{l}\text { Kara } \\
\text { putih }\end{array}$ & & \\
\hline & \multicolumn{4}{|c|}{ ton/ha } & & \\
\hline M (0 ton/ha)-S1(Tanpa) & 262 & 10,52 & 12,55 & 15,25 & $12,77 \mathrm{a}$ & \\
\hline M (4 ton/ha)-S2(Akar wangi) & 262 & 7,83 & 11,73 & 13,69 & $11,08 \mathrm{a}$ & 13,2 \\
\hline M (8 ton/ha)-S3(Tanaman jali) & 262 & 8,34 & 11,47 & 12,99 & $10,93 \mathrm{a}$ & 14,4 \\
\hline M (12 ton/ha)-S4(Rumput kolonjono) & 262 & 9,58 & 9,23 & 13,56 & $10,79 a$ & 15,52 \\
\hline Rata-rata & & $9,06 \mathrm{a}$ & $11,24 a b$ & $13,68 b$ & & \\
\hline
\end{tabular}

Keterangan: Angka yang diikuti huruf yang sama pada kolom atau baris yang sama menunjukkan tidak beda nyata pada uji DMRT (Duncan's Multiple Range Test) taraf $5 \%$.

\section{Gulma}

Hasil penelitian menunjukkan bahwa pada tanaman kara merah, kubis dan kara putih, perlakuan MS4 (mulsa batang jagung 12 ton/ha dengan rumput kolonjono+ srikaya sebagai penguat teras) menghasilkan berat kering gulma paling rendah yaitu $15,85 \mathrm{~g}$ dengan penurunan gulma 13,34\%. Pertumbuhan gulma dipengaruhi oleh kondisi lingkungan yaitu penyinaran dan naungan.

Menurut Radics dan Bognar (2012) mulsa batang jagung dapat menurunkan kerapatan gulma dan bobot kering gulma. Rendahnya bobot kering gulma diakibatkan oleh ruang tumbuh gulma dan cahaya matahari yang terbatas akibat tertutupi mulsa batang jagung. Mulsa batang jagung menutupi permukaan tanah sehingga sinar matahari yang dapat memecah dormansi biji-biji gulma terhalangi dan perkecambahan biji gulma terhambat.
Jenis gulma yang dominan pada penelitian ini adalah rumput teki (Cyperus rotundus L.) dan bandotan (Ageratum conyzoides L.). Ciri-ciri rumput teki yaitu batang berbentuk segitiga, kadang-kadang bulat dan tidak berongga, daun berasal dari nodia, dan berwarna ungu tua. Gulma dari golongan ini mempunyai sistem rhizome dan umbi sangat luas. Bandotan merupakan gulma semusim yaitu gulma yang hanya dapat hidup selama satu daur yang biasanya kurang dari satu tahun. Bandotan mempunyai ciri-ciri batang tumbuh tegak dengan percabangannya, daun majemuk dengan helaian daun bulat telur serta duduk daun berhadapan. Bandotan ini termasuk gulma yang tidak berbahaya namun jika dalam keadaan populasi tinggi harus dikendalikan (Sudiman 2010). 
Tabel 3. Pengaruh mulsa dan penguat teras terhadap berat kering gulma

\begin{tabular}{|c|c|c|c|c|c|}
\hline \multirow{3}{*}{ Mulsa(M)-Penguat teras(S) } & \multicolumn{3}{|c|}{ Blok } & \multirow{3}{*}{$\begin{array}{l}\text { Rata-rata } \\
\quad(\mathrm{g})\end{array}$} & \multirow{3}{*}{$\begin{array}{c}\text { Penurunan } \\
\text { gulma(\%) }\end{array}$} \\
\hline & Kara merah & Kubis & Kara putih & & \\
\hline & \multicolumn{3}{|c|}{$\left(g / 2 m^{2}\right)$} & & \\
\hline $\mathrm{M}(0$ ton/ha)-S1(Tanpa) & 17,70 & 17,45 & 19,80 & 18,31 & \\
\hline M (4 ton/ha)-S2(Akar wangi) & 17,29 & 16,28 & 18,87 & 17,48 & 4,53 \\
\hline M (8 ton/ha)-S3(Tanaman jali) & 15,76 & 16,74 & 18,93 & 17,14 & 6,38 \\
\hline M (12 ton/ha)-S4(Rumput kolonjono) & 14,45 & 15,66 & 17,44 & 15,85 & 13,34 \\
\hline Total & 65,20 & 66,13 & 75,04 & & \\
\hline
\end{tabular}

\section{Tinggi dan penutupan kanopi tanaman}

Secara umum perlakuan MS4 (mulsa batang jagung 12 ton/ha dengan rumput kolonjono+ srikaya sebagai penguat teras) menghasilkan tinggi tanaman tertinggi (Tabel 4). Pemberian mulsa batang jagung mampu menambah kandungan unsur hara berupa fosfor tersedia dan kalium (Sonsteby et al. 2010). Penelitian Dewi (2013) menunjukkan bahwa batang jagung mengandung selulosa dari zat lignin yang tinggi sehingga dapat meningkatkan bahan organik tanah.

Peningkatan pertumbuhan tanaman diduga pengaruh mulsa yang mampu mengurangi kehilangan air berlebihan akibat evaporasi sehingga kadar air dan suhu tanah tidak mengalami fluktuasi tajam (Dadah 2010). Perlakuan tanpa mulsa menyebabkan perubahan kandungan air tanah cukup besar, sehingga terjadi devisit air yang menghambat pertumbuhan tinggi tanaman. Kadar air tanah dalam kondisi kapasitas lapang mengakibatkan perakaran dapat berkembang dan menyerap larutan hara dengan baik.

Penyerapan hara yang baik ini digunakan untuk proses pertumbuhan tanaman. Peningkatan pertumbuhan selain disebabkan oleh persediaan air, juga dipengaruhi oleh persaingan dengan gulma berkurang. Mulsa batang jagung menutupi permukaan tanah sehingga sinar matahari yang dapat memecah dormansi biji-biji gulma terhalangi dan perkecambahan biji gulma terhambat.. Perlakuan MS4 dengan rumput kolonjono+ srikaya sebagai penguat teras) secara umum menghasilkan penutupan kanopi paling cepat pada tanaman kara merah, kubis dan kara putih (Tabel 4). Salah satu faktor yang mempengaruhi pertumbuhan kanopi tanaman adalah ketersediaan air. Semakin optimum air yang tersedia, maka semakin optimum pula pertumbuhan tanaman.

$\mathrm{Hal}$ ini sesuai dengan penelitian Arief (2013) bahwa mulsa dapat mencegah terjadinya evaporasi, dalam hal ini air yang menguap dari permukaan tanah akan ditahan oleh bahan mulsa dan jatuh kembali ke tanah. Lahan yang ditanami tidak akan kekurangan air karena penguapan air ke udara hanya terjadi melalui proses transpirasi. Mulsa batang jagung memberi pengaruh terhadap kelembaban tanah sehingga tercipta kondisi yang optimal untuk pertumbuhan tanaman. Sutarto (2013), menyatakan bahwa mulsa sisa tanaman mampu melindungi tanah dari pengaruh luar (sinar matahari dan curah hujan), sehingga air tanah dapat tersedia cukup bagi tanaman dan dapat mengurangi pemadatan tanah sehingga mengurangi fluktuasi suhu yang tajam.

Tabel 4. Pengaruh mulsa dan penguat teras terhadap tinggi dan penutupan kanopi tanaman pada 70 HST

\begin{tabular}{clcc}
\hline $\begin{array}{c}\text { Jenis } \\
\text { tanaman }\end{array}$ & Mulsa(M)-Penguat teras(S) & Tinggi tanaman (cm) & Penutupan kanopi (\%) \\
\hline Koro merah & M (0 ton/ha)-S1(Tanpa) & 53,42 & 60,04 \\
& M (4 ton/ha)-S2 (Akar wangi) & 59,10 & 65,31 \\
& M (8 ton/ha)-S3 (Tanaman jali) & 58,11 & 68,74 \\
& M (12 ton/ha)-S4 (Rumput & 64,85 & 74,27 \\
Kubis & kolonjono) & & 56,35 \\
& M (0 ton/ha)-S1(Tanpa) & 43,51 & 60,87 \\
& M (4 ton/ha)-S2 (Akar wangi) & 44,85 & 60,55 \\
& M (8 ton/ha)-S3 (Tanaman jali) & 45,42 & 65,23 \\
& M (12 ton/ha)-S4 (Rumput & 45,71 & 46,23 \\
& kolonjono) & & 50,41 \\
& M (0 ton/ha)-S1(Tanpa) & 53,28 & 50,52 \\
& M (4 ton/ha)-S2 (Akar wangi) & 56,86 & 56,23 \\
& M (8 ton/ha)-S3 (Tanaman jali) & 57,28 & \\
\hline
\end{tabular}




\section{Hasil tanaman}

Hasil penelitian menunjukkan bahwa perlakuan MS4 (mulsa batang jagung 12 ton/ha dan rumput kolonjono+srikaya sebagai penguat teras) menghasilkan berat segar, berat kering, polong segar, polong kering dan berat biji paling tinggi. Perlakuan MS4 mampu meningkatkan hasil biji kering 40,27\% (Tabel 6). Hasil tersebut berhubungan dengan pemberian mulsa batang jagung. Helda (2010) menyatakan bahwa pemberian mulsa batang jagung mempengaruhi pembentukan polong isi yang terbentuk.

Tabel 5. Pengaruh mulsa dan penguat teras terhadap hasil tanaman kara merah

\begin{tabular}{|c|c|c|c|c|c|c|}
\hline \multirow[t]{2}{*}{ Mulsa(M)-Penguat teras(S) } & $\begin{array}{c}\text { Bera } \\
t \\
\text { sega } \\
r\end{array}$ & $\begin{array}{r}\text { Berat } \\
\text { kering }\end{array}$ & $\begin{array}{l}\text { Polong } \\
\text { segar }\end{array}$ & $\begin{array}{l}\text { Polong } \\
\text { kering }\end{array}$ & Berat biji & \multirow[t]{2}{*}{$\begin{array}{l}\text { Peningkatan } \\
\text { hasil (\%) }\end{array}$} \\
\hline & \multicolumn{5}{|c|}{ (g/tanaman) } & \\
\hline $\mathrm{M}(0$ ton/ha)-S1(Tanpa) & 13,71 & 3,92 & 21,33 & 8,29 & 5,81 & \\
\hline M (4 ton/ha)-S2 (Akar wangi) & 16,85 & 4,48 & 25,14 & 9,54 & 6,81 & 28,05 \\
\hline M (8 ton/ha)-S3 (Tanaman jali) & 17,27 & 4,26 & 23,71 & 7,75 & 6,96 & 28,58 \\
\hline $\begin{array}{l}\text { M (12 ton/ha)-S4 (Rumput } \\
\text { kolonjono) }\end{array}$ & 18,11 & 5,24 & 29,69 & 11,39 & 8,15 & 40,27 \\
\hline
\end{tabular}

Hasil penelitian menunjukkan bahwa perlakuan MS4 (mulsa batang jagung 12 ton/ha dan rumput kolonjono+srikaya sebagai penguat teras) menghasilkan berat segar dan berat kering paling tinggi. Perlakuan MS4 mampu meningkatkan hasil kubis sebesar 57,10\% (Tabel 7). Hasil tersebut berhubungan dengan pemberian mulsa batang jagung. Yuwono (2008) menyatakan bahwa budidaya
Polong isi yang meningkat selajan dengan meningkatnya pertumbuhan kanopi atau tajuk yang berperan dalam menghasilkan asimilat dari fotosintesis. Proses pengisian polong lebih lama dan jumlah polong yang terisi pada perlakuan mulsa batang jagung lebih tinggi dibandingkan kontrol. Peningkatan jumlah polong isi akan meningkatkan bobot panen tanaman (Sudiman 2010).

dengan mulsa menyebabkan rata-rata pori aerasi tanah sedikit lebih tinggi dibanding tanpa mulsa. Pemakaian mulsa batang jagung dapat meningkatkan suhu minimum dan menurunkan suhu maksimum. Menurut Bertand (2009) fungsi mulsa dapat mencegah kehilangan air melalui evaporasi, memperkecil proses dispersi, memperbaiki struktur tanah, meningkatkan daya menahan air dan meningkatkan kapasitas infiltrasi.

Tabel 6. Pengaruh mulsa dan penguat teras terhadap hasil tanaman kubis

\begin{tabular}{|c|c|c|c|}
\hline \multirow{2}{*}{ Perlakuan } & Berat segar & Berat kering & \multirow{2}{*}{ Peningkatan hasil (\%) } \\
\hline & \multicolumn{2}{|c|}{ (g/tanaman) } & \\
\hline $\mathrm{M}(0$ ton/ha)-S1(Tanpa) & 857,42 & 60,07 & \\
\hline M (4 ton/ha)-S2 (Akar wangi) & 877,22 & 63,48 & 5.67 \\
\hline M (8 ton/ha)-S3 (Tanaman jali) & 982,21 & 66,96 & 11,46 \\
\hline $\begin{array}{l}\text { M (12 ton/ha)-S4 (Rumput } \\
\text { koloniono) }\end{array}$ & 1125,17 & 94,37 & 57,10 \\
\hline
\end{tabular}

Pengaruh perlakuan terhadap hasil tanaman menunjukkan bahwa perlakuan MS4 (mulsa batang jagung 12 ton/ha dan rumput kolonjono+srikaya sebagai penguat teras) menghasilkan berat segar, berat kering, polong segar, polong kering dan berat biji paling tinggi. Perlakuan MS4 mampu meningkatkan hasil biji kering kara putih sebesar $14,54 \%$ (Tabel 8 ).

Tabel 7. Pengaruh mulsa dan penguat teras terhadap hasil tanaman kara putih

\begin{tabular}{ccccccc}
\hline Mulsa(M)-Penguat teras(S) & $\begin{array}{r}\text { Berat } \\
\text { segar }\end{array}$ & $\begin{array}{c}\text { Berat } \\
\text { kering }\end{array}$ & $\begin{array}{c}\text { Polong } \\
\text { segar }\end{array}$ & $\begin{array}{c}\text { Polong } \\
\text { kering }\end{array}$ & $\begin{array}{c}\text { Berat } \\
\text { biji }\end{array}$ & $\begin{array}{c}\text { Peningkatan hasil } \\
(\%)\end{array}$ \\
\hline
\end{tabular}

Pemberian Mulsa dan Penguat Teras Pada Tiga Jenis Tanaman .......

Jaka S, Sumarno, Supriyono, Nanik karena meningkatnya pertumbuhan kanopi atau tajuk yang berperan dalam menghasilkan asimilat dari fotosintesis. Proses pengisian polong lebih lama dan jumlah polong yang terisi pada perlakuan mulsa batang jagung lebih tinggi dibandingkan kontrol (Helda 2010). 


\begin{tabular}{lcccccc} 
& \multicolumn{5}{c}{ (g/tanaman) } \\
\cline { 2 - 5 } M (0 ton/ha)-S1(Tanpa) & 28,16 & 15,26 & 34,21 & 19,86 & 16,5 \\
& & & & 0 \\
M (4 ton/ha)-S2 (Akar wangi) & 29,55 & 16,41 & 38,44 & 21,53 & 17,2 & 5 \\
& & & & & 17,0 & 3,54 \\
M (8 ton/ha)-S3 (Tanaman jali) & 29,95 & 16,11 & 38,37 & 21,01 & 2 & 15 \\
M (12 ton/ha)-S4 (Rumput & 32,33 & 17,42 & 40,11 & 23,14 & 18,9 & 14,54 \\
kolonjono) & & & tanahn
\end{tabular}

\section{KESIMPULAN DAN SARAN}

\section{Kesimpulan}

$\begin{array}{cl}\text { Berdasarkan penelitian yang telah } \\ \text { dilaksanakan, } & \text { dapat disimpulkan }\end{array}$ bahwaPemberian mulsa batang jagung 12 ton/ha dengan rumput kolonjono+srikaya sebagai penguat teras mampu menurunkan limpasan $4,46 \%$, erosi $15,52 \%$ dan berat kering gulma $13,43 \%$. Pemberian mulsa batang jagung 12 ton/ha dengan rumput kolonjono+srikaya sebagai penguat teras mampu menghasilkan pertumbuhan dan penutupan kanopi paling baik serta meningkatkan hasil tanaman kara merah $40,17 \%$, kubis $57,17 \%$ dan $15,58 \%$ kara putih.

\section{Saran}

Berdasarkan hasil penelitian tersebut maka pemberian mulsa batang jagung dengan dosis 12 ton/ha dan rumput kolonjono+srikaya sebagai penguat teras dapat diterapkan petani untuk mengurangi limpasan permukaan, erosi, dan meningkatkan pendapatan usahatani.

\section{UCAPAN TERIMAKASIH}

Penelitian ini merupakan bagian dari penelitian Dr. Ir. Jaka Suyana, M.Si dengan hibah STRANAS. Penulis mengucapkan terima kasih atas bantuan dan kesempatan yang diberikan untuk bekerja sama dalam penelitian ini.

\section{DAFTAR PUSTAKA}

Arief, S., 2013, Pengaruh takaran mulsa batang jagung terhadap pertumbuhan dan hasil tanaman kedelai (Glycine max L.), J Budidaya Pertanian, 10(20) : 12-25, ISSN: 2076-3125.

Bertand, 2009, Effect of different levels of wheat straw soil surface coverage on weed flora in vicia faba crops, J Agron, 20(21)189 : 233241, DOI: 10.17/jts2009.02110.

Blancocanqui, H., Gantzer, CJ., Anderson, SH. 2006, Performance of grass barriers and filter plant under interil and concentrated flow, Journal of Environmental Quality, 35(6) : 6974, DOI: 10.1104/PDIS-01-04-1251.

Dadah, 2010, Kajian pemberian air dan mulsa terhadap iklim mikro pada tanaman cabai di tanah entisol, J IImu Tanah dan Lingkungan, 4(1) : 41-49. ISSN: 2037-3112.

David, M., Richard, A., Rose, F. 2006, The process occurred of surface runoff, $J$ Conserv, 20(12) : 233-241, DOI: 10.201/jts2006.12720.

Djajadi, Mastur, Murdiyat, AS. 2008, Teknik konservasi untuk menekan erosi dan penyakit lincat pada lahan tembakau temanggung, J Littri, 14(3) : 101-106, ISSN: 2120-2927.

Endriani, Zurhalena, 2008, Kajian beberapa sifat fisika andisol pada beberapa penggunaan lahan dan kelerengan di Kecamatan Gunung Kerinci, Seminar Nasional Sains dan Teknologi, 2(1) : 75-80.

Helda, S. 2010, Pengaruh mulsa terhadap perkembangan gulma pada tanaman mentimun (Cucumis sativus L.), J Agron 27(1) : 16-21, ISSN: 1802-2103.

Henry, S. 2012, Teknik konservasi tanah untuk pengendalian erosi dan kehilangan hara serta efisiensi energi pada tanah Andisol di DAS Siulak, J Konservasi tanah, 10(4) : 98121, ISSN: 2230-3213.

Nearing, A., Jetten, B., Baffaut, Cerdan, O. 2007, Modeling response of soil erosion and runoff to changes in precipitation and cover, $\mathrm{J}$ Catena, 61 : 131-154, DOI: 10. 2012/PDIS05-12-2005.

Jacks, GV., Brind, W., Smith, R. 2007, Effect organic mulch to growth and yields of soybean (Glycine max L.), Soil science sosiety of american journal 49: 7-10, DOI: 10.4454/jpp.v92i2.177.

Ludwig, A., Bradford, P., David, B., Anton, W. 2007, Vegetation patches and runoff-erosion as interacting ecohydrological processes in semiarid landscapes, Ecology 86(2) : 288297, DOI: 10.22/AJB2010.04356.

Rachman, A., Gantzer, J., Anderson, SH. 2008, Soil hydraulic properties influenced by stiffstemmed grass hedge systems, Soil science sosiety of american journal, 68(7) : 86-93, 10.1329/AJB2005.23.2160.

Radics, Bognar, 2012, Improving soil with livestock manure, J Soil and water conserv, 40: 206-210. DOI: 10.24/AJB2007.03211. 
Rico, B., Smith, A. 2011, Agroforestry systems and soil surface management of a tropical alfisol: Water run off, soil erosion, and nutrient loss, J Soil Conserv 8 : 97-111, DOI: 10.1021/AJB2009.240.2100.

Sonsteby, A., Nes, A., Måge, 2010, Effects of bark mulch and NPK fertilizer on yield, leaf nutrien status and soil mineral nitrogen during three years of strawberry production, J Agron 54 : 128-134, DOI: 10.1901/PDIS04-11-1992.

Sudiman, A. 2010, Gulma dan pengendaliannya pada budidaya tanaman nilam, J Pertanian 4(2) : 40-52. URL: http://www.fp.ugm.ac.id.
Sutarto, 2013, Pengaruh pemberian mulsa (Chromolaena L.) pada kandungan mineral $\mathrm{P}$ dan $\mathrm{N}$ tanah latosol dan produktivitas hijauan jagung (Zea mays L.), J Agron 2(4) : 29-36, DOI: 10.1802/PDIS-11-09-1998.

Walling, A. 2008, Modelling interrill erosion in small cultivated catchments, J Hydrological process 16(16) : 215-226, DOI: 10.2114/jpp.v20i5.221.

Yuwono, 2008, Pemanfaatan mulsa dalam pertanian berkelanjutan, J Pertanian, 20(12) : 182-187, ISSN: 1873-2124. 